\title{
High Risk of New Knee Injuries in Female Soccer Players After Primary Anterior Cruciate Ligament Reconstruction at 5-to 10-Year Follow-up
}

Anne Fältström, Joanna Kvist and Martin Hägglund

The self-archived postprint version of this journal article is available at Linköping University Institutional Repository (DiVA):

http://urn.kb.se/resolve?urn=urn:nbn:se:liu:diva-180872

N.B.: When citing this work, cite the original publication.

Fältström, A., Kvist, J., Hägglund, M., (2021), High Risk of New Knee Injuries in Female Soccer Players After Primary Anterior Cruciate Ligament Reconstruction at 5-to 10-Year Follow-up, American Journal of Sports Medicine, , 03635465211044458. https://doi.org/10.1177/03635465211044458

Original publication available at:

https://doi.org/10.1177/03635465211044458

Copyright: SAGE Publications

http://www.uk.sagepub.com/home.nav 


\title{
High Risk of New Knee Injuries in Female Soccer Players After Primary ACL Reconstruction at 5- to 10-Years Follow-up
}

\begin{abstract}
Background: A new anterior cruciate ligament (ACL) injury after ACL reconstruction is a feared outcome.

Purpose: To study the risk of new knee injuries in female soccer players 5-10 years after primary unilateral ACL reconstruction, and compare players who returned to soccer with (1) players who did not return and (2) knee-healthy controls.

Study Design: Cohort study.
\end{abstract}

Methods: Demographic, soccer-specific, and surgical data were recorded at baseline for 317 female soccer players (mean age $\pm \mathrm{SD}, 20.1 \pm 2.7$ years) $1.6 \pm 0.7$ years after ACL reconstruction, and for 119 matched controls $(19.5 \pm 2.5$ years $)$. Data on new knee injuries and soccer playing status were collected 5-10 years after ACL reconstruction through a questionnaire.

Results: Among players with ACL reconstruction, 222 (70\%) responded at a mean $6.5 \pm 1.0$ years after primary ACL reconstruction. We compared 3 different cohorts: (1) 163 players with ACL reconstruction who returned to soccer; 68 (42\%) sustained 44 re-ruptures and 29 contralateral ruptures; (2) 59 players with ACL reconstruction who did not return to soccer; 11 (19\%) sustained 9 re-ruptures and 2 contralateral ruptures; and (3) 113 knee-healthy controls; 12 (11\%) sustained 13 ACL injuries. Players who returned had more than a 2-fold risk of a new ACL injury than players who did not return (risk ratio $[\mathrm{RR}] 2.24 ; 95 \% \mathrm{CI}, 1.27-3.93 ; P=.005$ ), and 4-fold higher risk than controls (RR 3.93; 95\% CI, 2.23-6.91; $P<.001$ ). A new ACL, meniscus, or cartilage injury was the most frequent new knee injury. Among players who returned to soccer, $68 \%$ reported a new knee injury and they had 2-5 times higher risk of any new knee injury and knee surgery than players who did not return and controls. 
Conclusions: Two-thirds of female soccer players with ACL reconstruction who returned to soccer sustained a new knee injury within 5-10 years; $42 \%$ had a new ACL injury. Their risk of new knee injury and knee surgery was 2-5 times greater than for players who did not return and for knee-healthy controls. New injury may have negative consequences for long-term knee health and should be a critical consideration in the decision to return to play.

Keywords: female; football; soccer; anterior cruciate ligament; return to sport; re-injury; retear What is known about the subject: Anterior cruciate ligament (ACL) injury is a severe injury in female soccer players. Return to sport after ACL reconstruction (ACLR) is often a desirable outcome for the injured athlete. More than half of players return to soccer after ACLR, but with a high risk of further ACL injury. To accurately describe the risk of new knee injuries in the long-term among female soccer players with ACLR, it is important to differentiate between those who return to soccer and those who quit soccer after ACLR. An age-matched control group would also be needed to establish the normal course of a female soccer player's participation in soccer and risk of knee injuries.

What this study adds to existing knowledge: Forty-two percent of female soccer players who returned to soccer after primary ACLR sustained a new ACL injury within 5-10 years after surgery. This was more than 2-fold and 4-fold higher risk compared with those who did not return to soccer and with knee-healthy controls, respectively. Among players who returned, 68\% reported a new knee injury (including ACL injuries) and 53\% had additional knee surgery after primary ACLR, which was a 2-5 times higher risk compared with players who did not return and with knee-healthy controls. Female soccer players with ACLR are at high risk of new knee injuries, which must be considered in the decision to return to play. More efforts toward secondary prevention strategies are needed. 


\section{INTRODUCTION}

Anterior cruciate ligament (ACL) injury is a severe injury and female soccer players are particularly at risk. ${ }^{38}$ Many athletes choose surgical treatment of the ACL injury to be able to return to sport (RTS) at the same level as before the injury. ${ }^{16}$ However, ACL reconstruction (ACLR) does not always ensure RTS and only about $46 \%$ to $67 \%$ of a female population with ACLR return to soccer. ${ }^{4,5,12,31,32}$ Younger players and those playing at high level are more likely to return to soccer. ${ }^{31}$ Returning to soccer after ACLR is paired with a high risk of new ACL injury to both knees, especially among young females. ${ }^{4,5,14,28,29,38,42}$ Up to one-third of female soccer player who return to soccer after ACLR sustain a new ACL injury within the first 3.5 years after ACLR. ${ }^{4,14}$ The incidence of new ACL injury, especially re-ruptures, seems to be highest in the first 2 to 3 years after ACLR. ${ }^{1}$ A high risk for other knee injuries has also been reported in soccer players with ACLR followed for 1 to 2 seasons. ${ }^{14,26,36}$ However, studies that report the incidence of all new knee injuries in the long-term - not only new ACL injuries - in female soccer players with ACLR, including knee-healthy controls, and distinguishing between those who return and those who do not return to soccer after ACLR are lacking. This is important since sport exposure is a key risk factor for new injury.

Knowledge about the risk of sustaining new knee injuries in female soccer players depending on whether they return to soccer or not is important for clinicians to be able to inform and advise patients before primary ACLR, in the rehabilitation process, and RTS decision. Therefore, long-term follow-up of the results regarding subsequent knee injuries after treatment and RTS is warranted.

The aim was to study the risk of new knee injuries in female soccer players, with a focus on new ACL injury, within 5-10 years after primary unilateral ACLR, and compare players who returned to soccer with (1) players who did not return and (2) knee-healthy controls. Our 
hypothesis was that players with ACLR who returned to soccer would have a higher risk of new knee injuries compared with players who did not return to soccer and compared with knee-healthy controls.

\section{METHODS}

This was a cohort study exploring new knee injuries among female soccer players 5 to 10 years after ACLR and among knee-healthy controls. Short-term data with 2-years follow-up (43.7 \pm 8.7 months after ACLR) have been published previously for 117 players (111 included in the current study) who returned to soccer after ACLR and for 119 controls. ${ }^{14}$

\section{Participants}

Female soccer players (playing at any level) aged 16 to 25 years with primary unilateral ACLR performed 6 to 36 months earlier (2010-2014) were identified from the Swedish National Knee Ligament Register (SNKLR) and additional advertising in 3 regional soccer districts. SNKLR captures $>90 \%$ of all ACLRs in Sweden. ${ }^{23}$ Exclusion criteria were having an associated posterior cruciate ligament injury and/or surgically treated injuries to either the medial or lateral collateral ligament. We identified 534 potentially eligible players in the SNKLR, and an additional 16 active players were recruited via advertisements (total $n=550$ ). A baseline survey was sent to the 550 players at the soccer pre-season (January to April) each new season from 2013 to 2015. Surgery data regarding the primary ACLR were collected from the SNKLR. Three hundred and seventeen players responded (mean age $\pm \mathrm{SD}$, $20.1 \pm 2.7$ years) $1.6 \pm 0.7$ years after ACLR and answered the baseline demographic and soccer-specific questions. These players (Figure 1) were then contacted for the long-term follow-up, 5-10 years after ACLR, with questions about soccer playing status and if they had sustained any new knee injuries, specifically ACL injuries and, if applicable, the circumstances and details about the injury. Significant new knee injuries were recorded by 
player self-reported in the survey based on the following two questions: 1) "Have you injured your ACL again or do you have ACL injuries in both knees?" and 2) "Have you sustained any other knee injuries after the first ACLR in any of the knees?" Both had binary response options yes or no. If the answer was "Yes" there were fixed response options with the possible responses: meniscus, ligament (MCL, LCL), PCL, patella luxation, cartilage or other injury (with options to specify and comment). Player-reported new ACL injuries were confirmed from the SNKLR or medical charts and at the same time other knee injuries that the players reported were also verified.

A.

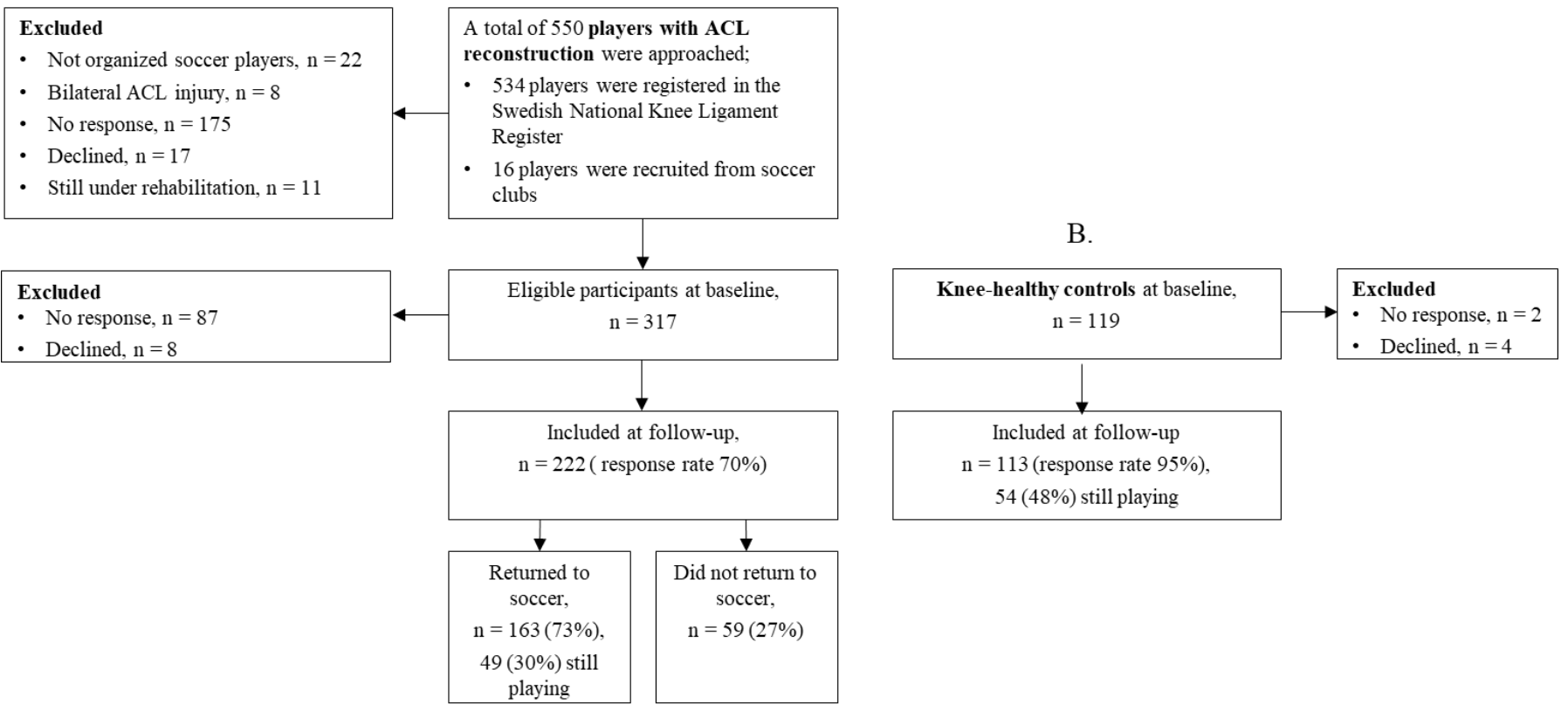

Figure 1. Study flowchart of female soccer players with anterior cruciate ligament (ACL) reconstruction (A) and the knee-healthy controls (B).

A matched control group regarding age was needed to establish the normal course of a female soccer player's participation in soccer and risk of subsequent knee injuries. ${ }^{35}$

Therefore, coaches recruited 119 knee-healthy controls to ensure similar age, soccer exposure, and playing position from the same teams as 117 of the active players with ACLR. ${ }^{14}$ 
All players received written information about the study and signed written consent. The study was approved by the Swedish Ethical Review Authority (Dnr 2012/24-31, 2013/75-32, 2017/324-32 and 2020-01093) and the SNKLR board.

\section{Statistical Methods}

All statistical analyses were performed in SPSS Statistics for Windows (IBM SPSS Statistics for Windows, Version 26.0. IBM, Armonk, NY). Descriptive statistics are presented as mean $\pm \mathrm{SD}$ or median with interquartile range (IQR), and range. Normality and homogeneity of variance were evaluated for continuous data. Between-group comparisons of continuous data were analyzed with Student's $t$ test if appropriate or the Mann-Whitney U test. Chi-squared test or Fisher's exact test was utilized for between-group comparisons of categorical data. The risk of (1) new ACL injuries, (2) other new knee injuries, and (3) knee injuries treated with surgery were compared between players who returned to soccer after ACLR and the 2 other groups (players who did not return to soccer after ACLR and kneehealthy controls). Between-group risk ratios (RRs) with a 95\% confidence interval (CI) are presented. Baseline data are presented in different strata regarding the risk of sustaining a new ACL injury: (1) age at primary ACLR, (2) time between injury and primary ACLR, (3) graft diameter, (4) concomitant injury at primary ACLR, (5) ACLR in the dominant limb (preferred kicking leg) or nondominant limb, (6) body mass index (BMI) categorized according to World Health Organization nutritional status,${ }^{40}$ and (7) level of play. The risk was calculated as $\left[\mathrm{N}_{\text {with new ACL injury }} / \mathrm{N}_{\text {total for the group }}\right] \times 100$. The significance level was set at $P<.05$.

\section{RESULTS}

Of the 317 eligible players with ACLR, 222 responded (response rate 70\%) at mean \pm SD $6.5 \pm 1.0$ years (range, 5.0-9.9 years) after ACLR. Of the 119 controls, 113 (response rate 95\%) answered the questionnaire (Figure 1). For the players with ACLR and for the controls, 
the mean \pm SD time since answering the baseline questionnaire was $4.8 \pm 0.8$ and $5.0 \pm 0.7$ years, respectively.

The 3 cohorts thus consisted of (1) 163 players with ACLR who returned to soccer after primary ACLR, of whom 49 (30\%) were still active soccer players at follow-up; (2) 59 players who never returned to soccer after the primary ACLR; and (3) 113 knee-healthy controls, of whom 54 (48\%) were still active soccer players at follow-up (Figure 1).

\section{Non-responders}

Non-responders at baseline $(n=95)$ did not differ significantly from responders $(n=222)$ regarding age at the time of ACLR, time between injury and primary ACLR, graft diameter at primary ACLR, presence of concomitant injuries at primary ACLR or additional ACLR according to the SNKLR at follow-up $(P>.05)$. However, there were significantly more hamstring grafts $(98 \%$ vs $92 \%, P=.005)$ among the responders, and significantly more responders returned to soccer compared with non-responders, $73 \%$ vs $44 \%(P<.001)$.

\section{Baseline Data}

Descriptive data for players with ACLR and the knee-healthy controls are presented in Table 1. 


\section{TABLE 1}

Demographic Data in Female Soccer Players with ACLR Who Did or Did Not Return to Soccer and KneeHealthy Controls ${ }^{a}$

\begin{tabular}{|c|c|c|c|c|c|c|}
\hline & \multicolumn{4}{|c|}{ Players with ACLR } & \multirow{2}{*}{\multicolumn{2}{|c|}{$\begin{array}{l}\text { Knee-Healthy Controls } \\
\qquad(\mathrm{n}=113)\end{array}$}} \\
\hline & \multicolumn{2}{|c|}{$\begin{array}{l}\text { Returned to Soccer } \\
(\mathrm{n}=163)\end{array}$} & \multicolumn{2}{|c|}{$\begin{array}{l}\text { Did Not Return to } \\
\text { Soccer }(\mathrm{n}=59)\end{array}$} & & \\
\hline & Baseline & Follow-up & Baseline & Follow-up & Baseline & Follow-up \\
\hline Age, years & $20.0 \pm 2.6$ & $24.9 \pm 2.7$ & $20.1 \pm 2.9$ & $24.9 \pm 3.1$ & $19.5 \pm 2.5$ & $24.5 \pm 2.6$ \\
\hline Height, $\mathrm{cm}$ & $168 \pm 5.0$ & $168 \pm 5.0$ & $167 \pm 6.0$ & $168 \pm 6.0$ & $167 \pm 6.0$ & $167 \pm 6.0$ \\
\hline Body mass index, $\mathrm{kg} / \mathrm{m}^{2}$ & $22.3 \pm 2.2^{b}$ & $23.2 \pm 2.6$ & $22.6 \pm 2.3^{c}$ & $23.5 \pm 3.5$ & $22.1 \pm 2.0$ & $22.8 \pm 2.4$ \\
\hline \multicolumn{7}{|l|}{ Occupation } \\
\hline Worker & $110(31)^{b}$ & $108(66)$ & $12(26)^{d}$ & $39(66)$ & $30(27)$ & $77(68)$ \\
\hline Student & $49(69)$ & $55(34)$ & $35(74)$ & $20(34)$ & $83(73)$ & $36(32)$ \\
\hline \multicolumn{7}{|l|}{ Dominant limb } \\
\hline Right & \multicolumn{2}{|c|}{$147(90)$} & \multicolumn{2}{|c|}{$56(95)$} & \multicolumn{2}{|c|}{$109(96)$} \\
\hline Left & \multicolumn{2}{|c|}{$16(10)$} & \multicolumn{2}{|c|}{$3(5)$} & \multicolumn{2}{|c|}{$4(4)$} \\
\hline
\end{tabular}

${ }^{a}$ Values are reported as means $\pm \mathrm{SD}$ or $\mathrm{n}(\%)$. ACLR, anterior cruciate ligament reconstruction; SD, standard deviation.

${ }^{b}$ Missing data, $\mathrm{n}=4$.

${ }^{c}$ Missing data, $\mathrm{n}=13$.

${ }^{d}$ Missing data, $\mathrm{n}=12$.

Factors related to the primary ACL injury for the players with ACLR who returned to soccer and those who did not are presented in Table 2. 


\section{TABLE 2}

Baseline Data at Primary ACLR in Female Soccer Players Who Did or Did Not Return to Soccer ${ }^{a}$

\begin{tabular}{|c|c|c|c|}
\hline & \multicolumn{2}{|c|}{ Players with ACLR } & \multirow[b]{2}{*}{$\begin{array}{c}P \\
\text { Value }\end{array}$} \\
\hline & $\begin{array}{l}\text { Returned to } \\
\text { Soccer } \\
(\mathrm{n}=163)\end{array}$ & $\begin{array}{c}\text { Did Not } \\
\text { Return to } \\
\text { Soccer } \\
(\mathrm{n}=59)\end{array}$ & \\
\hline Age at $\mathrm{ACLR}$, mean $\pm \mathrm{SD}$, years & $18.4 \pm 2.6$ & $18.4 \pm 2.9$ & .977 \\
\hline $\begin{array}{l}\text { Time between injury and ACLR, median (IQR; range), } \\
\text { months }\end{array}$ & $4.5(5 ; 0-68)$ & $6(9 ; 2-87)$ & .001 \\
\hline$<3$ months & $56(34)$ & $7(12)$ & \\
\hline $3-12$ months & $93(57)$ & $35(59)$ & \\
\hline$>12$ months & $14(9)$ & $17(29)$ & \\
\hline Graft: all autografts & & & .601 \\
\hline \multicolumn{4}{|l|}{ Hamstrings } \\
\hline 1- to 4-strand semitendinosus & $76(48)$ & $31(55)$ & \\
\hline Semitendinosus gracilis & $84(52)$ & $25(45)$ & \\
\hline Patellar tendon & $2(1)$ & $1(2)$ & \\
\hline Quadriceps tendon & $1(1)$ & & \\
\hline Graft diameter & & & .020 \\
\hline$<8.0 \mathrm{~mm}$ & $60(37)$ & $32(54)$ & \\
\hline$\geq 8.0 \mathrm{~mm}$ & $103(63)$ & $27(46)$ & \\
\hline Fixation in femur & & & .015 \\
\hline Cortical suspension devices & $153(96)^{b}$ & $50(85)$ & \\
\hline Intratunnel fixation & $7(4)$ & $9(15)$ & \\
\hline Fixation in tibia & & & .423 \\
\hline Cortical suspension devices & $64(40)^{c}$ & $27(46)$ & \\
\hline Intratunnel fixation & $97(60)$ & $32(54)$ & \\
\hline Index knee ACLR & & & .977 \\
\hline Right & $86(53)$ & $31(53)$ & \\
\hline Left & $77(47)$ & $28(47)$ & \\
\hline ACLR in the dominant limb (preferred kicking leg) & $90(55)$ & $32(54)$ & .897 \\
\hline \multicolumn{4}{|l|}{ Presence of concomitant injuries at ACLR } \\
\hline Meniscal surgery medial, repair & $14(9)$ & $5(8)$ & .979 \\
\hline Meniscal surgery medial, resection & $9(6)$ & $7(12)$ & .139 \\
\hline Meniscal surgery lateral, repair & $8(5)$ & $5(8)$ & .338 \\
\hline Meniscal surgery lateral, resection & $26(16)$ & $5(8)$ & .156 \\
\hline Articular cartilage injury & $14(9)$ & $7(12)$ & .461 \\
\hline Surgically treated (\% of cartilage injuries) & $1(1)$ & $0(0)$ & \\
\hline
\end{tabular}

${ }^{a}$ Values are reported as $\mathrm{n}(\%)$ unless otherwise stated. ACLR, anterior cruciate ligament reconstruction; SD, standard deviation; IQR, interquartile range. Bolded $P$ values indicate statistically significant between-group differences.

${ }^{b}$ Missing data, $\mathrm{n}=3$.

${ }^{c}$ Missing data, $\mathrm{n}=3$.

\section{New ACL Injury During Follow-up}

During follow-up, 68 players (42\%) with ACLR who returned to soccer sustained 73 new ACL injuries (44 re-ruptures; 29 contralateral ruptures). Of the 73 new ACL injuries, 59 
$(81 \%)$ occurred when playing soccer and 39 of those $(66 \%)$ were non-contact. Twenty-three players (34\%) returned to soccer after the second ACL injury and $3(4 \%)$ had the intention to return (still under rehabilitation). In players who did not return to soccer after ACLR, 11 (19\%) sustained 11 new ACL injuries (9 re-ruptures; 2 contralateral ruptures). In the kneehealthy control group, 12 players (11\%) sustained 13 ACL injuries, $11(85 \%)$ occurred in soccer and 9 of those $(82 \%)$ were non-contact.

Players with ACLR who returned to soccer had more than a 2-fold higher risk of a new ACL injury compared with players who did not return (RR, 2.24; 95\% CI, 1.27-3.93; $P=.005$ ), and 4-fold higher risk compared with the knee-healthy control group (RR 3.93; 95\% CI, 2.23-6.91; $P<.001$ ) (Table 3).

Time from primary ACLR to a new ACL injury was median 25 (IQR 32, range 8-95) months for players who returned to soccer, and 25 (IQR 18, range 2-67) months for players who did not return $(P=.357)$ (Figure 2$)$. Time from primary ACLR to re-rupture was median 25 (IQR 21, range 2-67) months and for a contralateral ACL injury 27 (IQR 36, range 9-95) months $(P=.189)$ (Figure 3). Among the players with ACLR, 60 of the 84 new ACL injuries (71\%) were reconstructed. In the knee-healthy control group, 11 of the 13 ACL injuries (85\%) were reconstructed. 


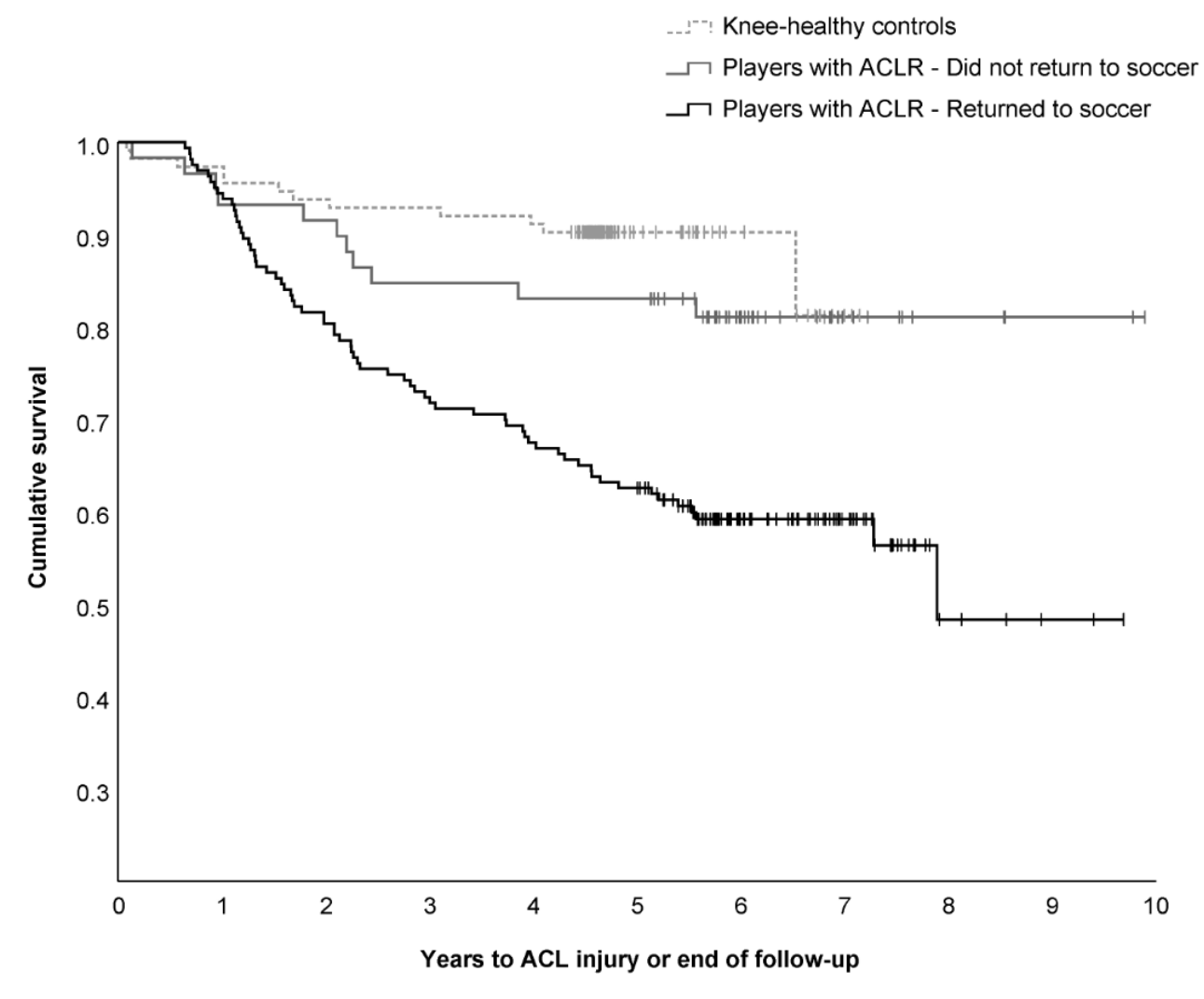

Figure 2. Kaplan-Meier curve showing years from primary anterior cruciate ligament (ACL) reconstruction (ACLR) to new ACL injury in players with ACLR who did or did not return to soccer. Knee-healthy controls are reported from baseline. 


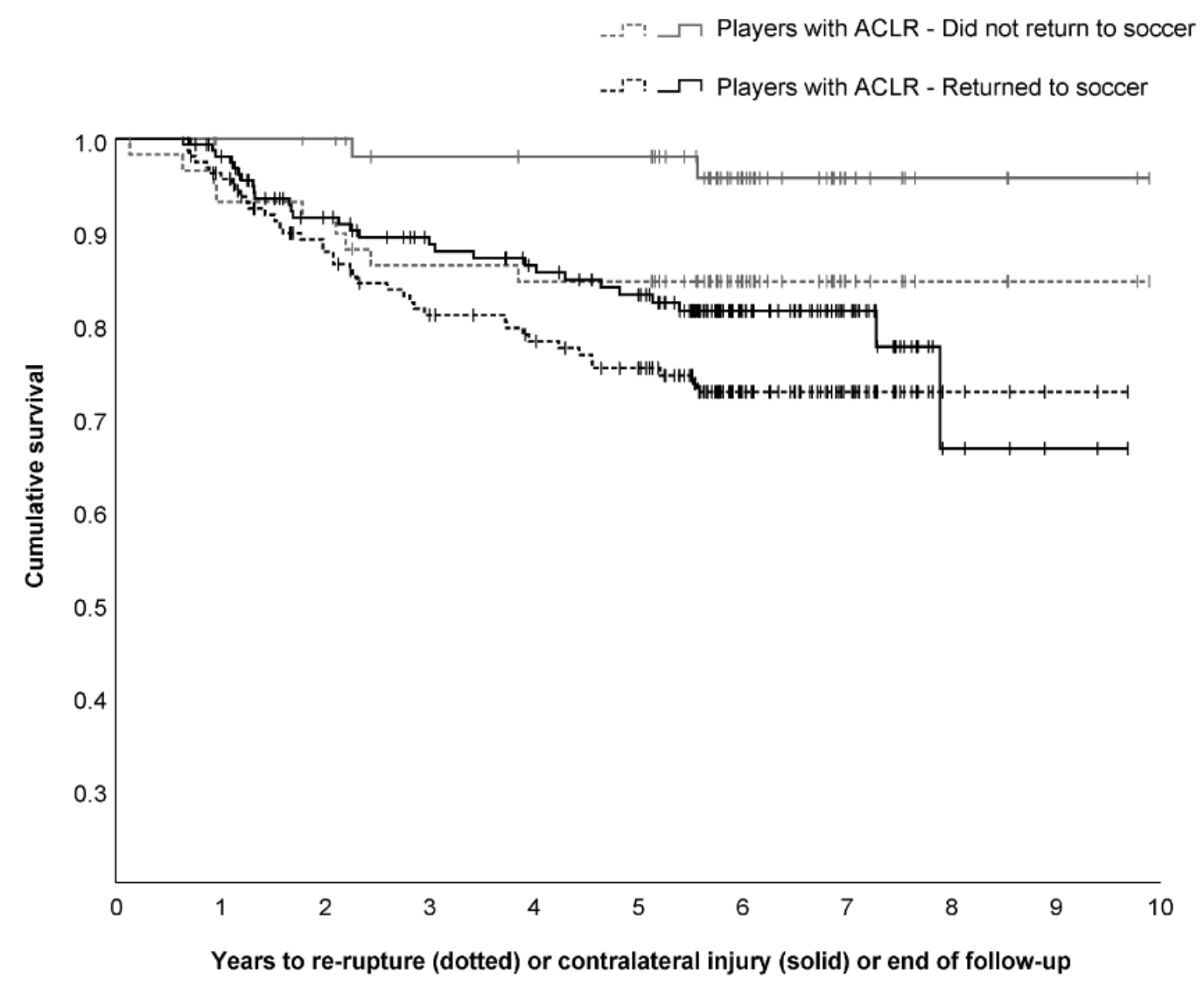

Figure 3. Kaplan-Meier curve showing years from primary anterior cruciate ligament (ACL) reconstruction (ACLR) to re-rupture (dotted lines) or contralateral ACL injury (solid lines) in players with ACLR who did or did not return to soccer.

\section{New Knee Injury During Follow-up}

New knee injury (including ACL injury) during follow-up was reported by 111 players (68\%) who returned to soccer compared with 20 players (34\%) who did not return (RR, 2.01; 95\% CI, 1.39-2.91; $P<.001)$, and by 29 players $(26 \%)$ in the knee-healthy control group (RR 2.65; 95\% CI 1.91-3.69; $P<.001$ ). Other new knee injuries (excluding ACL injury) during follow-up were reported by 77 (47\%) players who returned to soccer compared with 15 players $(25 \%)$ in the group who did not return (RR, 1.86; 95\% CI, 1.17-2.96; $P=.009)$ and by 18 players (16\%) in the knee-healthy control group (RR, 2.97; 95\% CI, 1.88-4.67; $P<.001)$. The proportion of other non-ACL knee injuries that were treated surgically did not differ between players who returned (68 of 106 injuries, 64\%) and those who did not return 
(12 of 25 injuries, $48 \%)(P=.136)$, but was higher compared with the knee-healthy controls (4 of 23 injuries, 17\%) $(P<.001)$ (Table 3).

The risk of a new ACL injury stratified according to different baseline factors for players with ACLR who returned to soccer or not and knee-healthy controls is presented in Table 4. In players with ACLR who returned to soccer, the stratification of the risk of new ACL injury based on different baseline factors showed that the youngest age group (59\% risk), those playing at elite level (60\% risk), those with no associated concomitant injury at primary ACLR (46\% risk), and players with a quick primary ACLR $(<3$ months after injury, $50 \%$ risk) had a high risk of new ACL injury. In players with ACLR who did not return to soccer, those who had a quick primary ACLR had a noteworthy high risk of new ACL injury (57\%). 
TABLE 3

New Knee Injuries Reported from Baseline to 5-10 Year Follow-Up in Players with ACL Reconstruction and Knee-Healthy Controls ${ }^{a}$

\begin{tabular}{|c|c|c|c|c|c|c|c|c|}
\hline & \multicolumn{4}{|c|}{ Players with ACLR } & \multirow{2}{*}{\multicolumn{2}{|c|}{$\begin{array}{c}\text { Knee-Healthy } \\
\text { Controls }(\mathrm{n}=113)\end{array}$}} & \multicolumn{2}{|c|}{ Risk ratio $(95 \% \mathrm{CI}) ; P$ value } \\
\hline & \multicolumn{2}{|c|}{$\begin{array}{c}\text { Returned to } \\
\text { Soccer }(\mathrm{n}=163)\end{array}$} & \multicolumn{2}{|c|}{$\begin{array}{l}\text { Did Not Return to } \\
\text { Soccer }(\mathrm{n}=59)\end{array}$} & & & Returned vs Did Not Return & Returned vs Controls \\
\hline & No. & & No. & & No. & $\%$ & & \\
\hline Total no. of players with new ACL injury & 68 & 42 & 11 & 19 & 12 & 11 & $2.24(1.27-3.93) ; P=.005$ & $3.93(2.23-6.91) ; P<.001$ \\
\hline Re-rupture & 44 & $27^{b}$ & 9 & 15 & & & $1.79(0.93-3.44) ; P=.080$ & \\
\hline Contralateral rupture & 29 & $18^{c}$ & 2 & 3 & 1 & $1^{d}$ & $5.25(1.29-21.32) ; P=.020$ & \\
\hline Total no. of players with new knee injury & 111 & 68 & 20 & 34 & 29 & 26 & $2.01(1.39-2.91) ; P<.001$ & $2.65(1.91-3.69) ; P<.001$ \\
\hline Only new ACL injury & 34 & 21 & 5 & 8 & 11 & 10 & & \\
\hline New ACL injury + other knee injury & 34 & 21 & 6 & 10 & 1 & 1 & & \\
\hline Other knee injury only (excl. ACL) & 43 & 27 & 9 & 15 & 17 & 15 & & \\
\hline $\begin{array}{l}\text { Total no. of players with new knee injury (excl. } \\
\text { ACL) }\end{array}$ & 77 & 47 & 15 & 25 & 18 & 16 & $1.86(1.17-2.96) ; P=.009$ & 2.97 (1.88-4.67); $P<.001$ \\
\hline 1 injury & 56 & 34 & 6 & 10 & 15 & 13 & & \\
\hline 2 injuries & 16 & 10 & 8 & 14 & 1 & 2 & & \\
\hline 3 injuries & 3 & 2 & 1 & 2 & 2 & 2 & & \\
\hline 4 or 5 injuries & 2 & 1 & & & & & & \\
\hline Total no. of players treated with knee surgery & 85 & 52 & 16 & 27 & 12 & 11 & $1.92(1.23-3.00) ; P=.004$ & $4.91(2.82-8.56) ; P<.001$ \\
\hline No. and specification of new knee injuries & $\begin{array}{l}\text { ACLR } \\
\text { knee }\end{array}$ & $\begin{array}{l}\text { Contra- } \\
\text { lateral }\end{array}$ & $\begin{array}{l}\text { ACLR } \\
\text { knee }\end{array}$ & $\begin{array}{l}\text { Contra- } \\
\text { lateral }\end{array}$ & $\begin{array}{l}\text { Non- } \\
\text { dominant }\end{array}$ & Dominant & & \\
\hline ACL injury & 44 & 29 & 9 & 2 & 6 & 7 & & \\
\hline Meniscus lesion & 46 & 6 & 11 & 1 & 1 & 3 & & \\
\hline Medial or lateral collateral ligament injury & 7 & 6 & 7 & 1 & 4 & 5 & & \\
\hline Cartilage lesion & 18 & 1 & 2 & & 1 & & & \\
\hline Patella subluxation & 2 & & & 1 & & 2 & & \\
\hline Joint sprain-unspecified & & & & & 1 & & & \\
\hline Baker's cyst & & & 1 & & & & & \\
\hline Graft problems (fixation, scar tissue) & 4 & & & & & & & \\
\hline Pain, instability, locking & 5 & 5 & & & & 6 & & \\
\hline Loose body & 2 & & 1 & & & & & \\
\hline Jumper's/runner's knee & 3 & 1 & & & & & & \\
\hline
\end{tabular}


TABLE 4

Risk of New ACL Injury in Players with ACLR and Knee-Healthy Controls, Stratified into Different Baseline Factors and Specified as Re-rupture or Contralateral ACL

Injury in Players Who Returned ${ }^{a}$

\begin{tabular}{|c|c|c|c|c|c|c|c|c|c|c|c|c|c|c|c|c|c|c|}
\hline \multirow{5}{*}{ Baseline data } & \multicolumn{14}{|c|}{ Players with ACLR } & \multirow{2}{*}{\multicolumn{4}{|c|}{$\begin{array}{l}\text { Knee-Healthy Controls } \\
\qquad(\mathrm{n}=113)\end{array}$}} \\
\hline & \multicolumn{10}{|c|}{ Returned to Soccer $(n=163)$} & \multicolumn{4}{|c|}{$\begin{array}{l}\text { Did Not Return to Soccer } \\
(\mathrm{n}=59)\end{array}$} & & & & \\
\hline & \multirow{3}{*}{$\mathrm{N}$} & \multicolumn{9}{|c|}{ New ACL injury } & \multirow{2}{*}{\multicolumn{4}{|c|}{$\begin{array}{l}\text { New ACL Injury } \\
\quad(\mathrm{n}=11)\end{array}$}} & \multirow{3}{*}{$\mathrm{N}$} & \multirow{2}{*}{\multicolumn{3}{|c|}{ ACL Injury $(n=12)$}} \\
\hline & & \multicolumn{3}{|c|}{$\begin{array}{l}\text { Re-rupture or CACL } \\
\text { Injury }(\mathrm{n}=68)\end{array}$} & \multicolumn{3}{|c|}{ Re-rupture $(n=44)$} & \multicolumn{3}{|c|}{ CACL Injury $(n=29)$} & & & & & & & & \\
\hline & & $\mathrm{n}$ & $\begin{array}{l}\text { Risk } \\
(\%)\end{array}$ & $(95 \% \mathrm{CI})$ & $\mathrm{n}$ & $\begin{array}{c}\text { Risk } \\
(\%)\end{array}$ & $(95 \% \mathrm{CI})$ & $\mathrm{n}$ & $\begin{array}{c}\text { Risk } \\
(\%)\end{array}$ & $(95 \% \mathrm{CI})$ & & $\mathrm{n}$ & $\begin{array}{c}\text { Risk } \\
(\%)\end{array}$ & $(95 \% \mathrm{CI})$ & & $\mathrm{n}$ & $\begin{array}{l}\text { Risk } \\
(\%)\end{array}$ & $(95 \% \mathrm{CI})$ \\
\hline \multicolumn{19}{|l|}{ Age at primary ACLR } \\
\hline$<16$ years & 29 & 17 & 59 & $(41-77)$ & 9 & 31 & $(14-48)$ & 10 & 34 & $(17-52)$ & 16 & 3 & 19 & $(0-38)$ & & & & \\
\hline $16-18$ years & 72 & 30 & 42 & $(30-53)$ & 19 & 26 & $(16-37)$ & 13 & 18 & $(9-27)$ & 19 & 5 & 26 & $(7-46)$ & $57^{b}$ & 7 & 12 & $(4-21)$ \\
\hline $19-21$ years & 42 & 12 & 29 & $(15-42)$ & 8 & 19 & $(7-31)$ & 5 & 12 & $(2-22)$ & 16 & 1 & 6 & $(0-18)$ & $28^{b}$ & 3 & 11 & $(0-22)$ \\
\hline$\geq 21$ years & 20 & 9 & 45 & $(23-67)$ & 8 & 40 & $(19-61)$ & 1 & 5 & $(0-15)$ & 8 & 2 & 25 & $(0-55)$ & $28^{b}$ & 2 & 7 & $(0-17)$ \\
\hline \multicolumn{19}{|l|}{$\begin{array}{l}\text { Time between injury and } \\
\text { primary ACLR }\end{array}$} \\
\hline$<3$ months & 56 & 28 & 50 & $(37-63)$ & 22 & 39 & $(26-52)$ & 9 & 16 & $(6-26)$ & 7 & 4 & 57 & $(20-94)$ & & & & \\
\hline 3-12 months & 93 & 36 & 39 & $(29-49)$ & 20 & 22 & $(13-30)$ & 17 & 18 & $(10-26)$ & 35 & 4 & 11 & $(1-22)$ & & & & \\
\hline$>12$ months & 14 & 4 & 29 & $(5-52)$ & 2 & 14 & $(0-33)$ & 3 & 23 & $(0-46)$ & 17 & 3 & 18 & $(0-36)$ & & & & \\
\hline \multicolumn{19}{|l|}{ Graft diameter } \\
\hline$<8.0 \mathrm{~mm}$ & 60 & 27 & 45 & $(32-58)$ & 16 & 27 & $(15-38)$ & 13 & 22 & $(11-32)$ & 32 & 8 & 25 & $(10-40)$ & & & & \\
\hline$\geq 8.0 \mathrm{~mm}$ & 103 & 41 & 40 & $(30-49)$ & 28 & 27 & $(19-36)$ & 16 & 16 & $(9-23)$ & 27 & 3 & 11 & $(0-23)$ & & & & \\
\hline \multicolumn{19}{|l|}{$\begin{array}{l}\text { Concomitant injury at } \\
\text { primary ACLR }\end{array}$} \\
\hline Yes & 56 & 19 & 34 & $(22-46)$ & 12 & 21 & $(11-32)$ & 8 & 14 & $(5-23)$ & 20 & 4 & 20 & $(2-38)$ & & & & \\
\hline No & 107 & 49 & 46 & $(36-55)$ & 32 & 30 & $(21-39)$ & 21 & 20 & $(12-27)$ & 39 & 7 & 18 & $(6-30)$ & & & & \\
\hline \multicolumn{19}{|l|}{ ACLR side } \\
\hline Nondominant & 73 & 28 & 38 & $(27-50)$ & 20 & 27 & $(17-38)$ & 11 & 15 & $(7-23)$ & 27 & 4 & 15 & $(1-28)$ & & & & \\
\hline Dominant & 90 & 40 & 44 & $(34-55)$ & 24 & 27 & $(18-36)$ & 18 & 20 & $(12-28)$ & 32 & 7 & 22 & $(8-36)$ & & & & \\
\hline \multicolumn{19}{|l|}{ Level of play ${ }^{c}$} \\
\hline Elite (top 2 divisions) & 15 & 9 & 60 & $(35-85)$ & 7 & 47 & $(21-72)$ & 3 & 20 & $(0-40)$ & & & & & 13 & 2 & 15 & $(0-35)$ \\
\hline $3^{\text {rd }}-6$ th division & 123 & 49 & 40 & $(31-48)$ & 30 & 24 & $(17-32)$ & 21 & 17 & $(10-24)$ & 29 & 6 & 21 & $(6-35)$ & 88 & 10 & 11 & $(5-18)$ \\
\hline $\begin{array}{l}\text { Lowest division or youth } \\
\text { play }\end{array}$ & 20 & 6 & 30 & $(10-50)$ & 5 & 25 & $(6-44)$ & 2 & 10 & $(0-23)$ & 16 & 3 & 19 & $(0-38)$ & 12 & 0 & 0 & \\
\hline \multicolumn{19}{|l|}{ Body mass index, $\mathrm{kg} / \mathrm{m}^{d}$} \\
\hline$<24.9$, normal weight & 135 & 57 & 42 & $(34-51)$ & 37 & 27 & $(20-35)$ & 25 & 19 & $(12-25)$ & 37 & 8 & 22 & $(8-35)$ & 97 & 11 & 11 & $(5-18)$ \\
\hline$\geq 25.0$, overweight & 24 & 8 & 33 & $(14-52)$ & 6 & 25 & $(8-42)$ & 2 & 8 & $(0-19)$ & 9 & 1 & 11 & $(0-32)$ & 16 & 1 & 6 & $(0-18)$ \\
\hline
\end{tabular}


${ }^{b}$ Age reported at baseline.

${ }^{c}$ Missing data for players with ACLR who returned, $\mathrm{n}=5$, and did not return, $\mathrm{n}=14$.

$13{ }^{d}$ Missing data for players with ACLR who returned, $\mathrm{n}=4$, and did not return, $\mathrm{n}=13$. 


\section{DISCUSSION}

$$
\text { Returning to a sport that involves contact and pivoting after an ACLR resulted in a high }
$$
risk of sustaining subsequent new knee injuries in our cohort of female soccer players. Twothirds of the players who returned to soccer after primary ACLR sustained a new knee injury, and $42 \%$ sustained a new ACL injury, within 5 to 10 years. Half of the players who returned after primary ACLR had additional surgical treatment for new knee injuries.

We found a 2-fold risk of new ACL injury in players who returned to soccer after ACLR compared with those who did not return, and a 4-fold higher risk compared with knee-healthy soccer playing controls. The alarmingly high risk of new ACL injury (42\%) after primary ACLR and return to soccer is concerning, and even higher than in previous reports.

Depending on the time of follow-up (2-10 years), previous studies have shown a risk of new ACL injury ranging from $20 \%$ to $34 \%{ }^{1,4,5,14,31}$ after return to soccer in females with ACLR. In line with our results, the risk of new ACL injury in those who did not return is reported to be significantly lower, ranging from $4 \%$ to $15 \% .^{1,4,31}$ Our results confirm the high risk of new ACL injuries after ACLR in the long term, which is disappointing given that surgical techniques ${ }^{30}$ and rehabilitation approaches are constantly evolving, and stresses the importance of implementing effective secondary prevention strategies. Sprinting skills are becoming more and more important in modern soccer with faster players, ${ }^{20}$ potentially leading to more high-risk actions being performed at higher speeds, and higher sporting demands may partly explain the lack of decline in subsequent ACL injuries after primary ACLR.

4 In our study, more re-ruptures (27\%) were reported compared with contralateral injuries (18\%). The re-ruptures occurred in a median 25 months after primary ACLR compared with 27 months for the contralateral injuries. There are conflicting reports on whether the risk of re-rupture and contralateral injury differs after primary ACLR and return to contact sports. ${ }^{1,5}$, 
17, 29, 42 Contralateral ruptures/reconstructions often occur later than re-ruptures/revisions after primary ACLR, ${ }^{1,13}$ and relatively more contralateral ruptures are reported in longer follow-up studies. ${ }^{1,24,31}$ Therefore, more contralateral ruptures could be expected to occur in future follow-ups of our cohort.

Players who returned to soccer had a 5 times higher risk of contralateral ACL injury compared with players who did not return, and the risk difference for a re-rupture was lower (risk ratio, 1.79; non-significant). Previous studies report conflicting results regarding players who returned or did not return and differences in re-ruptures and contralateral ruptures, where only difference in the rate of re-ruptures, ${ }^{1}$ contralateral ruptures ${ }^{24}$ or both re-ruptures and contralateral ruptures ${ }^{31}$ are reported.

Nearly $50 \%$ of the players who returned to soccer reported a new knee injury other than ACL injury, predominately to the menisci, cartilage, collateral ligaments, or patella, or reported other knee problems such as gradual onset pain and instability, with a 2- to 3-fold higher risk than those who did not return and the controls. Approximately half of the reported knee injuries were treated with surgery compared with $17 \%$ of the knee injuries in the control group, indicating that more serious injuries were incurred in players with ACLR. Grindem et al ${ }^{17}$ reported that patients with ACLR who returned to high-level pivoting sports had a more than 4 times higher rate of re-injury - with the meniscus being the most frequently injured knee structure - compared with patients who returned to sports that were less demanding on the knees within the first 2 years after ACLR. The high rate of new knee injuries after return to soccer after ACLR is equally concerning, because meniscal injury or meniscectomy increases the risk of osteoarthritis. ${ }^{39}$ One of the reasons for undergoing ACLR of the injured ACL is to avoid additional injury to the meniscus and cartilage. ${ }^{11}$ Our data clearly show that the discussion should also be directed toward the high risk of further knee injury associated with return to pivoting sports after ACLR and the potential long-term negative effects. 
Our stratification of the risk of new ACL injury based on different baseline factors showed that players of younger age, playing at elite level, having no associated concomitant injury at primary ACLR, and with a quick primary ACLR (less than 3 months after injury) had the highest risk of sustaining a new ACL injury. This finding is in line with previous reports showing that young age, ${ }^{13,42}$ playing at elite level, ${ }^{36,37}$ and short time from injury to ACLR ${ }^{13}$ increase the risk of subsequent ACL injury. We have previously shown that these same factors are associated with a high rate of return to soccer after ACLR ${ }^{12}$ and probably reflects a group of highly motivated females who desire a rapid return to soccer, but also obviously have an alarmingly high risk of new ACL injury.

Associated concomitant injury at primary ACLR negatively affects the likelihood of patients returning to soccer 1 year after ACLR. ${ }^{19}$ Therefore, having no associated concomitant injury could mean that the player's rehabilitation is quicker, risking a premature $\mathrm{RTS}^{9}$ and insufficient time for rehabilitation and graft healing. RTS before 8 to 9 months after ACLR increases the risk for new knee injuries. ${ }^{9,}{ }^{17}$ However, a previous report on meniscus injuries at primary ACLR did not predict subsequent ACL injury in either knee. ${ }^{22}$

Other factors such as limb dominance of the primary ACLR and BMI had no association with risk of new ACL injury. This is in contrast to a previous study reporting that primary ACLR on the nondominant side increased the risk for contralateral ACL injury in soccer players. ${ }^{5}$ There are studies in general populations reporting differences regarding high BMI, with lower, ${ }^{10}$ higher, ${ }^{34}$ or no difference in risk of new ACL injury. ${ }^{21}$ In our study, the graft size in players who did not return to soccer graft was smaller compared with those who returned and had a higher risk of new ACL injury (25\% vs $11 \%)$. This is in line with previous reports regarding hamstring graft size $<8 \mathrm{~mm}$ with higher risk of re-rupture, ${ }^{18}$ early ACL revision, ${ }^{33}$ and lower RTS. $^{18}$ 
The discussion about the surgical procedure and subsequent ACL injuries must also continue. In our study, 98\% had hamstring tendon autografts which makes comparisons with other graft options meaningless. It is likely that ACLR needs to be performed with respect to different treatment options and in a more individual way (e.g. patient functional demands) ${ }^{30}$ and based on surgeon preference and experience. ${ }^{41}$

Studies imply that many ACL re-injuries can be prevented with optimal rehabilitation., 7 Self-perceived function, functional performance, and strength improve 9 to 24 months after sport participation, and performed in modern times (2010-2014), which contrasts with most studies on outcomes after returning to sport after ACLR. ${ }^{2,42}$ Another strength was the confirmation of reported new ACL injuries both from a national knee ligament register and

108 from medical charts. This allowed analysis of the overall risk of new ACL injuries, which is 109 impossible in pure surgical register-based studies because only additional ACLRs are 110 reported..$^{13}$ The relatively long follow-up after ACLR of 5 to 10 years is also a strength, 111 because the risk of additional ACL injury is confounded by time. ${ }^{1,28,29,42}$ The response rate 
112 was excellent for the controls (95\%) and acceptable for players with ACLR (70\%). The

113 careful dropout analysis between responders and non-responders is a strength and showed no 114 major differences.

115 Our study also has some limitations. The inclusion procedure with participants recruited via

116 advertisement on the homepages of 3 regional soccer districts, in addition to the SNKLR,

117 might have led to a selection bias and overestimation of players who returned to soccer.

118 However, the main purpose was not to report the RTS rate, and we believe that the influence

119 on our overall results is minimal. We included players at a range of 6-36 months after ACLR

120 because the time point of return to sport can vary widely. Most additional ACLR registered in

121 the SNKLR occur within the first 3 post-operative years. ${ }^{13}$ Thus, at baseline many players had

122 already "survived" the most critical period for additional ACLR, because we did not send the

123 survey to players registered for additional ACLR. We have no detailed data about soccer

124 exposure during the follow-up, which is a limitation because soccer exposure time is a key

125 risk factor for new injury. Previous studies show that players with ACLR have less match

126 exposure than controls, ${ }^{3,25}$ indicating that the true risk of subsequent knee injury after ACLR

127 in female soccer athletes may be even higher than that reported in our study. Finally, since

128 this was a long-term follow-up of a previously established cohort of soccer players with

129 ACLR and knee-healthy controls, we did not perform an a priori sample size calculation. We

130 do, however, believe our study is adequately sized for our main research question.

\section{CONCLUSIONS}

132 Two-thirds of female soccer players with ACLR who returned to soccer sustained a new

133 knee injury, and 42\% sustained a new ACL injury, during the 5- to 10-year follow-up. Their

134 risk of new knee injury and knee surgery was 2 to 5 times greater than for players who did not

135 return and for knee-healthy controls. The alarmingly high risk of new knee injuries after 
136 ACLR in female soccer players, with potential negative effects on long-term knee health,

137 should be a critical consideration in the decision to return to play decision. More efforts for 138 secondary prevention are needed.

\section{REFERENCES}

140 1. Allen MM, Pareek A, Krych AJ, et al. Are female soccer players at an increased risk of second anterior cruciate ligament injury compared with their athletic peers? Am J

2. Ardern CL, Taylor NF, Feller JA, Webster KE. Fifty-five per cent return to competitive sport following anterior cruciate ligament reconstruction surgery: an updated systematic review and meta-analysis including aspects of physical functioning and contextual factors. Br J Sports Med. 2014;48(21):1543-1552.

3. Arundale AJH, Silvers-Granelli HJ, Snyder-Mackler L. Career length and injury incidence after anterior cruciate ligament reconstruction in major league soccer players. Orthop J Sports Med. 2018;6(1):2325967117750825.

4. Britt E, Ouillette R, Edmonds E, et al. The challenges of treating female soccer players with ACL injuries: hamstring versus bone-patellar tendon-bone autograft. Orthop $J$ Sports Med. 2020;8(11):2325967120964884.

5. Brophy RH, Schmitz L, Wright RW, et al. Return to play and future ACL injury risk after ACL reconstruction in soccer athletes from the Multicenter Orthopaedic Outcomes Network (MOON) group. Am J Sports Med. 2012;40(11):2517-2522.

6. Buckthorpe M. Optimising the late-stage rehabilitation and return-to-sport training and testing process after ACL reconstruction. Sports Med. 2019;49(7):1043-1058. 
158 7. Buckthorpe M, Della Villa F. Optimising the 'mid-stage' training and testing process after ACL reconstruction. Sports Med. 2020;50(4):657-678.

160

161

162

163

164

165

166

167

168

169

170

171

172

173

174

175

176

177

8. Curran MT, Bedi A, Kujawa M, Palmieri-Smith R. A cross-sectional examination of quadriceps strength, biomechanical function, and functional performance from 9 to 24 months after anterior cruciate ligament reconstruction. Am J Sports Med. 2020;48(10):2438-2446.

9. Della Villa F, Hägglund M, Della Villa S, Ekstrand J, Waldén M. High rate of second ACL injury following ACL reconstruction in male professional footballers: an updated longitudinal analysis from 118 players in the UEFA Elite Club Injury Study. Br $J$ Sports Med. 2021. doi: 10.1136/bjsports-2020-103555. Epub ahead of print. PMID: 33846157.

10. DiSilvestro KJ, Jauregui JJ, Glazier E, et al. Outcomes of anterior cruciate ligament reconstruction in obese and overweight patients: a systematic review. Clin J Sport Med. 2019;29(4):257-261.

11. Fok AW, Yau WP. Delay in ACL reconstruction is associated with more severe and painful meniscal and chondral injuries. Knee Surg Sports Traumatol Arthrosc. 2013;21(4):928-933.

12. Fältström A, Hägglund M, Kvist J. Factors associated with playing football after anterior cruciate ligament reconstruction in female football players. Scand J Med Sci Sports. 2016;26(11):1343-1352.

13. Fältström A, Hägglund M, Magnusson H, Forssblad M, Kvist J. Predictors for additional anterior cruciate ligament reconstruction: data from the Swedish national ACL register. Knee Surg Sports Traumatol Arthrosc. 2016;24(3):885-894. 
181 14. Fältström A, Kvist J, Gauffin H, Hägglund M. Female soccer players with anterior cruciate ligament reconstruction have a higher risk of new knee injuries and quit soccer to a higher degree than knee-healthy controls. Am J Sports Med. 2019;47(1):3140.

15. Gilchrist J, Mandelbaum BR, Melancon H, et al. A randomized controlled trial to

16. Grevnerts HT, Kvist J, Fältström A, Sonesson S. Patients focus on performance of physical activity, knee stability and advice from clinicians when making decisions concerning the treatment of their anterior cruciate ligament injury. Int J Sports Phys Ther. 2020;15(3):441-450.

17. Grindem H, Snyder-Mackler L, Moksnes H, Engebretsen L, Risberg MA. Simple decision rules can reduce reinjury risk by $84 \%$ after ACL reconstruction: the Delaware-Oslo ACL cohort study. Br J Sports Med. 2016;50(13):804-808.

18. Gupta R, Kapoor A, Soni A, Khatri S, Masih GD, Mittal N. Does hamstring tendon graft diameter affect the outcome of anterior cruciate ligament surgery? Sports Orthopaedics and Traumatology. 2019;35(2):166-170.

19. Hamrin Senorski E, Svantesson E, Beischer S, et al. Low 1-year return-to-sport rate after anterior cruciate ligament reconstruction regardless of patient and surgical factors: a prospective cohort study of 272 patients. Am J Sports Med. 2018;46(7):1551-1558.

20. Haugen T, Tønnessen E, Hisdal J, Seiler S. The role and development of sprinting speed in soccer. Int J Sports Physiol Perform. 2014;9(3):432-441. 
21. Ifran NN, Mok YR, Krishna L. Tear rates of the ipsilateral ACL graft and the contralateral native ACL are similar following ACL reconstruction. J Knee Surg. 2020; [Epub ahead of print] PMID: 32659816.

22. Kaeding CC, Pedroza AD, Reinke EK, Huston LJ, Spindler KP. Risk factors and predictors of subsequent ACL injury in either knee after ACL reconstruction: Prospective analysis of 2488 primary ACL reconstructions from the MOON cohort. Am J Sports Med. 2015;43(7):1583-1590.

23. Kvist J, Kartus J, Karlsson J, Forssblad M. Results from the Swedish national anterior cruciate ligament register. Arthroscopy. 2014;30(7):803-810.

24. Lindanger L, Strand T, Mølster AO, Solheim E, Inderhaug E. Return to play and longterm participation in pivoting sports after anterior cruciate ligament reconstruction. $\mathrm{Am}$ J Sports Med. 2019;47(14):3339-3346.

25. Niederer D, Engeroff T, Wilke J, Vogt L, Banzer W. Return to play, performance, and career duration after anterior cruciate ligament rupture: a case-control study in the five biggest football nations in Europe. Scand J Med Sci Sports. 2018;28(10):2226-2233.

26. Nilstad A, Andersen TE, Bahr R, Holme I, Steffen K. Risk factors for lower extremity injuries in elite female soccer players. Am J Sports Med. 2014;42(4):940-948.

27. Nyland J, Greene J, Carter S, Brey J, Krupp R, Caborn D. Return to sports bridge program improves outcomes, decreases ipsilateral knee re-injury and contralateral knee injury rates post-ACL reconstruction. Knee Surg Sports Traumatol Arthrosc. 2020;28(11):3676-3685. 
28. Paterno MV, Rauh MJ, Schmitt LC, Ford KR, Hewett TE. Incidence of contralateral and ipsilateral anterior cruciate ligament (ACL) injury after primary ACL reconstruction and return to sport. Clin J Sport Med. 2012;22(2):116-121.

29. Paterno MV, Rauh MJ, Schmitt LC, Ford KR, Hewett TE. Incidence of second ACL injuries 2 years after primary ACL reconstruction and return to sport. Am J Sports Med. 2014;42(7):1567-1573.

30. Patrick W, Shady EM, Christoph T, Ramin K, Xaver F. Advanced anterior cruciate ligament repair and reconstruction techniques for different rupture types. Arthrosc Tech. 2020;9(7):e969-e977.

31. Sandon A, Engstrom B, Forssblad M. High risk of further anterior cruciate ligament injury in a 10-year follow-up study of anterior cruciate ligament-reconstructed soccer players in the Swedish National Knee Ligament Registry. Arthroscopy. 2020;36(1):189-195.

32. Sandon A, Werner S, Forssblad M. Factors associated with returning to football after anterior cruciate ligament reconstruction. Knee Surg Sports Traumatol Arthrosc. 2015;23(9):2514-2521.

33. Snaebjornsson T, Hamrin-Senorski E, Svantesson E, et al. Graft diameter and graft type as predictors of anterior cruciate ligament revision: a cohort study including 18,425 patients from the Swedish and Norwegian National Knee Ligament Registries. J Bone Joint Surg Am. 2019;101(20):1812-1820.

34. Snaebjornsson T, Svantesson E, Sundemo D, et al. Young age and high BMI are predictors of early revision surgery after primary anterior cruciate ligament 
reconstruction: a cohort study from the Swedish and Norwegian knee ligament registries based on 30,747 patients. Knee Surg Sports Traumatol Arthrosc. 2019.

35. Stein SM, Mandelbaum BR. Editorial commentary: Anterior cruciate ligament injury and reconstruction in soccer players: The major challenge is always going for our goals! Arthroscopy. 2020;36(1):196-198.

36. Waldén M, Hägglund M, Ekstrand J. High risk of new knee injury in elite footballers with previous anterior cruciate ligament injury. Br J Sports Med. 2006;40(2):158-162; discussion 158-162.

37. Waldén M, Hägglund M, Magnusson H, Ekstrand J. ACL injuries in men's professional football: a 15-year prospective study on time trends and return-to-play rates reveals only $65 \%$ of players still play at the top level 3 years after ACL rupture. Br J Sports Med. 2016;50(12):744-750.

38. Waldén M, Hägglund M, Werner J, Ekstrand J. The epidemiology of anterior cruciate ligament injury in football (soccer): a review of the literature from a gender-related perspective. Knee Surg Sports Traumatol Arthrosc. 2011;19(1):3-10.

39. van Meer BL, Meuffels DE, van Eijsden WA, Verhaar JA, Bierma-Zeinstra SM, Reijman M. Which determinants predict tibiofemoral and patellofemoral osteoarthritis after anterior cruciate ligament injury? A systematic review. Br J Sports Med. 2015;49(15):975-983.

40. Weir CB, Jan A. BMI classification percentile and cut off points. StatPearls. Treasure Island (FL): StatPearls Publishing; 2020. 
268 41. Widner M, Dunleavy M, Lynch S. Outcomes Following ACL Reconstruction Based on Graft Type: Are all Grafts Equivalent? Curr Rev Musculoskelet Med. 2019;12(4):460-465.

271 42. Wiggins AJ, Grandhi RK, Schneider DK, Stanfield D, Webster KE, Myer GD. Risk of secondary injury in younger athletes after anterior cruciate ligament reconstruction: a systematic review and meta-analysis. Am J Sports Med. 2016;44(7):1861-1876. 